\title{
Characterization of Modified Lampung Natural Zeolite with Cetyl Trimethyl Ammonium Bromide (CTAB) for Adsorption Industrial Tapioca Wastewater
}

\author{
Darmansyah $^{1, *}$ S B Ginting ${ }^{1}$ D A Iryani ${ }^{1}$ R P Sari ${ }^{1}$ D Supriyadi ${ }^{2}$ \\ ${ }^{1}$ Departement of Chemical Engineering, Universitas Lampung, Bandar Lampung, Indonesia \\ ${ }^{2}$ Departement of Chemical Engineering, Institut Teknologi Sumatera, Bandar Lampung, Indonesia \\ *Corresponding author. Email:darmansyah82@gmail.com
}

\begin{abstract}
This research was observed on the CTAB modified Lampung Natural Zeolite (ZMS). The aim is to improve the adsorption capacity of tapioca wastewater. This zeolite modification process has several steps, starts with Lampung Natural Zeolite (ZAL or LNZ) pretreatment, $\mathrm{LNZ}$ activation by $\mathrm{NH}_{4} \mathrm{Cl}$, and ends up with adding CTAB in four different of concentrations; $0.5 \mathrm{mM}, 1 \mathrm{mM}, 10 \mathrm{mM}$, and $100 \mathrm{mM}$. Resulting of ZMS was characterized by FTIR, XRD, SEM, and BET. FTIR results showed that the modification of ZAL with $\mathrm{CTAB}$ was successfully carried out on all variations of concentration. All of the ZMS formed has asymmetric and symmetric vibrations $-\mathrm{CH}_{2}$ which show the presence of CTAB crystals and methylene scissoring. According to the figures shown by XRD results, CTAB modified zeolite for all concentration variations showed several peaks with $2 \theta$ diffraction angles that were identical to the peak identities of clinoptilolite and albite. The SEM results showed that ZMS has an identical morphological structure consists of crystals and slightly amorphous. Based on the material performance in adsorbing tapioca wastewater, the highest percentage of COD reduction was found in ZMS 4 adsorption with a pore average size of $74.9755 \AA$, surface area of $10.893 \mathrm{~m}^{2} / \mathrm{g}$ is $48.8 \%$.
\end{abstract}

Keywords: Adsorption, CTAB modified natural zeolite, synthesis, tapioca wastewater

\section{INTRODUCTION}

Cassava is one of the main food crop commodities in Lampung. Lampung is one of the largest provinces producing cassava in Indonesia with a harvest area of 279,337 ha and in total the production of 7,387,084 tons of cassava per year. This very high level of cassava production has encouraged the establishment of more than 70 tapioca industries which are spread throughout the regions in Lampung with a diverse scale of production [1]. The existence of the tapioca industry can improve the economy of the surrounding community but can also have a negative impact in the form of liquid waste produced. To avoid this negative impact, it is necessary to process it first before tapioca liquid waste was discharged into the environment. One process that can be done to reduce the content of organic matter was by the adsorption process. Adsorption is defined as a process of diffusion of molecules from fluid to the surface of solid adsorbents [2].
The adsorption process starts with the movement of most adsorbates from the fluid to the adsorbent film layer. Then, the adsorbate diffuses towards the surface of the adsorbent until it is absorbed into the inner pore surface of the adsorbent. The absorbed substance is called adsorbate while the material that functions as an absorbent is called an adsorbent [4]. The adsorbent commonly used in the process of separation or purification is zeolite. Natural zeolite is a micropore mineral formed from hydrated aluminosilicate crystals with a three-dimensional structure consisting of $\left[\mathrm{SiO}_{4}\right]^{4-}$ and $\left[\mathrm{AlO}_{4}\right]^{5-}[9]$. Many natural zeolites are available and have low prices. In addition, high cation exchange capacity and large surface area.

However, the permanent negative charge contained in the zeolite structure makes natural zeolite have a low adsorption performance for organic material in aqueous solutions, especially in tapioca wastewater. Thus, zeolites need to be modified to improve the ability to remove organic pollutants [3]. Some researchers have 
succeeded in modifying zeolites with surfactants used as adsorbents to remove various pollutants such as Sodium Dodecyl Benzene Sulfonate by Taffarel and Rubio [9] and Perchloroethylene (PCE) by $\mathrm{Li}$ and Bowman [7]. The results of these studies indicate that natural zeolite has enormous potential in handling liquid waste. In this study, modification of Lampung Natural Zeolite will be carried out using CTAB to increase the ability of its adsorption to tapioca wastewater. The zeolite modification process is carried out by adding CTAB in four variations of concentration: $0.5 \mathrm{mM}, 1 \mathrm{mM}, 10$ $\mathrm{mM}$, and $100 \mathrm{mM}$.

At low concentrations, the positive charge on the ammonium group in CTAB will stick to the surface of the negatively charged zeolite so that the outer surface of the zeolite will form a surfactant monolayer. If the concentration is increased to exceed the concentration of critical micelles, the alkyl chain will interact hydrophobically to form a bilayer that makes the outer surface of the zeolite positive. This positively charged outer surface is able to absorb anions or organic compounds in waste [9]. In terms of utilization, adsorption of tapioca wastewater is carried out. Organic material contained in tapioca liquid waste consists of carbohydrates, fiber, fat, and protein. This organic material is largely non-polar, so it can be adsorbed by the modified CTAB zeolite. This adsorption occurs because of the hydrophobic interaction between modified CTAB zeolite material and non-polar organic matter. Decreasing non-polar organic matter will reduce COD levels in tapioca wastewater.

\section{MATERIALS AND METHODS}

\subsection{MATERIALS}

Lampung Natural Zeolites were obtained from CV. Minatama, $\mathrm{NH}_{4} \mathrm{Cl}$ (pro analysis) obtained from Mecrk $\mathrm{KGaA}$, Cetyltrimethylammonium bromide (CTAB) (pro analysis) obtained from Mecrk $\mathrm{KGaA}$, distilled water, liquid tapioca waste, COD reagent.

\subsection{METHODS}

\subsubsection{Zeolite pretreatment}

Zeolite that has been obtained from CV. Minatama was first reduced in size by using mortar which was then sifted using a 200 mesh sieve. Zeolites that pass the 200 mesh sieve are washed and soaked using distilled water for 24 hours. Then filtered and dried with an oven at $110^{\circ} \mathrm{C}$ for 24 hours.

\subsubsection{Zeolite activation}

30 grams of zeolite from the pre-treatment were then immersed in $200 \mathrm{~mL}$ of $1.5 \mathrm{M} \mathrm{NH}_{4} \mathrm{Cl}$ solution and stirred using a magnetic stirrer $350 \mathrm{rpm}$ for 12 hours atroom temperature. Then zeolite was filtered and washed with distilled water to neutral $\mathrm{pH}$. Then, zeolite is calcined using a furnace at $350^{\circ} \mathrm{C}$ for 9 hours and stored in a desiccator. The result of activation is called zeolite-H.

\subsubsection{Zeolite modification}

A total of 7 grams of zeolite-H was reacted with 100 $\mathrm{ml}$ of CTAB with a concentration of $0.5 \mathrm{mM}$ (ZMS 1); 1 $\mathrm{mM}$ (ZMS 2); $10 \mathrm{mM}$ (ZMS 3); $100 \mathrm{mM}$ (ZMS 4). The mixture is stirred using a magnetic stirrer $150 \mathrm{rpm}$ for 24 hours at room temperature. The mixture is filtered and washed with distilled water to neutral $\mathrm{pH}$. Then zeolite is dried in an oven at $70^{\circ} \mathrm{C}$ for 5 hours. The result of this modification is called ZMS (Surfactant Modified Zeolite).

\subsubsection{Adsorption experiment}

Add 1 gram of adsorbent to the Erlenmeyer that has been filled with $100 \mathrm{~mL}$ tapioca wastewater (ratio1:10). The mixture is stirred using a magnetic stirrer $600 \mathrm{rpm}$ for 2 hours at room temperature. Then the sample was filtered to separate solids and liquids. The filtrate is ready for COD analysis. $2.5 \mathrm{~mL}$ of tapioca wastewater was pipetted into a tube containing a digestive solution $(1.5 \mathrm{~mL})$ and a solution of sulfuric acid reactor $(3.5 \mathrm{~mL})$ (COD reagent). Then the tube is shaken slowly until homogeneous. The tube was then placed on the COD reactor, which was heated at $150^{\circ} \mathrm{C}$, and reflux it for 2 hours. The refluxed sample is cooled slowly to room temperature. Then for sample, the value of COD is measured using spectrophotometry. Aquadest are used as blanks in COD measurements.

\section{RESULTS AND DISCUSSION}

\subsection{FOURIER TRANSMISSION INFRA-RED (FTIR)}

FTIR analysis was carried out at UPT Integrated Laboratory and Technology Innovation Center, University of Lampung. FTIR CTAB modified zeolite spectra are shown in Figure1.The interpretation of the results obtained is adjusted to the typical absorption data of natural zeolite and CTAB presented in Table 1. For natural zeolite, the major bands of aluminosilicate at wave numbers $300-1300 \mathrm{~cm}^{-1}$. Wave number $420-500$ $\mathrm{cm}^{-1}$ is internal stretching vibration $\mathrm{Si}-\mathrm{O} / \mathrm{Al}-\mathrm{O}$ while the external stretching vibration $\mathrm{Si}-\mathrm{O} / \mathrm{Al}-\mathrm{O}$ is shown at wave number $700-780 \mathrm{~cm}^{-1}$. The symmetrical range of $\mathrm{O}-\mathrm{Si}-\mathrm{O}$ and $\mathrm{O}-\mathrm{Al}-\mathrm{O}$ is shown at wave numbers $680-850$ $\mathrm{cm}^{-1}$ while the asymmetrical range $\mathrm{O}-\mathrm{Si}-\mathrm{O}$ and $\mathrm{O}-\mathrm{Al}-\mathrm{O}$ are shown at wave numbers $900-1250 \mathrm{~cm}^{-1}$ [5]. Other absorption bands that appear on natural zeolites found in wave numbers $1630-1640 \mathrm{~cm}-1$ are $\mathrm{H}-\mathrm{O}-\mathrm{H}$ bending vibrations which are adsorbed into zeolites and 3000$3700 \mathrm{~cm}-1$ which are asymmetric and symmetrical overlap H-O-H with hydroxyl groups of zeolites [9]. 
The strongest absorption band showing the presence of CTAB crystals occurs at wave numbers $2915 \mathrm{~cm}-1$ and $2850 \mathrm{~cm}-1$ where this absorption band is asymmetric and symmetric - $\mathrm{CH} 2$. In addition, absorption bands in 1461-1476 cm-1 showed methylene scissoring [9].

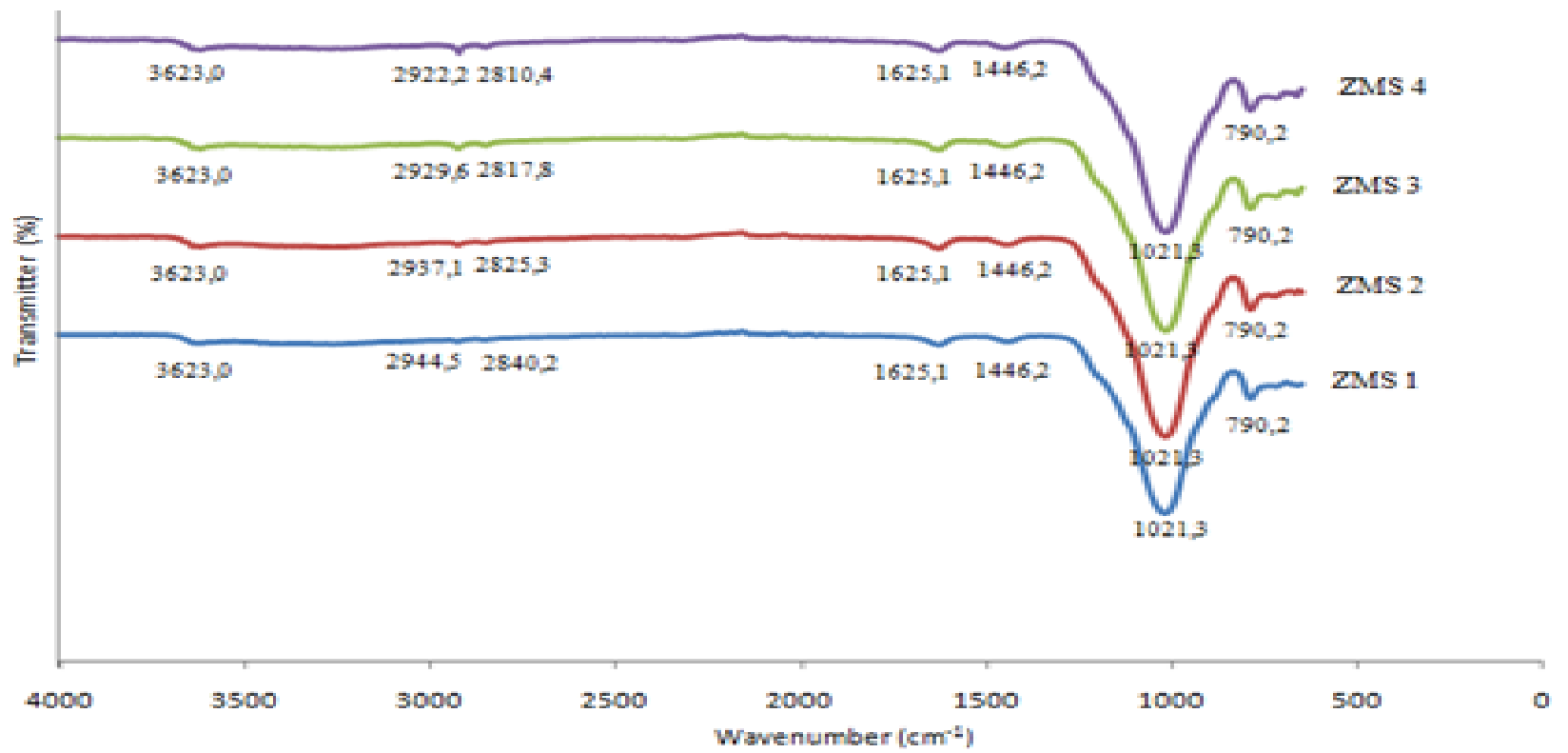

Figure 1 FTIR Spectra of Surfactant Modified Zeolite

On ZMS 1, the absorption appeared at wavelengths of $2944.5 \mathrm{~cm}-1$ and $2840.2 \mathrm{~cm}-1$ which showed asymmetric and symmetrical $\mathrm{CH} 2$. For ZMS 2, the absorption band shows a slight shift at the wavelength of 2937.1 and $2825.3 \mathrm{~cm}-1$. For ZMS 3, it appears that the absorption band looks sharper and re-shifts slightly at the wavelength of $2929.7 \mathrm{~cm}-1$ and $2817.8 \mathrm{~cm}-1$. And On ZMS 4, the absorption peak at wave number 2922.2 $\mathrm{cm}-1$ and $2810.4 \mathrm{~cm}-1$ this result means it is sharper than the previous three ZMS.

Table 1. Comparison FTIR of Sample with Standard of FTIR Natural Zeolite and CTAB

\begin{tabular}{|c|c|c|c|c|c|}
\hline \multicolumn{2}{|c|}{ Natural zeolite (Hamdan, 1992) } & \multirow{2}{*}{ ZMS 1} & \multirow{2}{*}{ ZMS 2} & \multirow{2}{*}{ ZMS 3} & \multirow{2}{*}{ ZMS 4} \\
\hline Vibration & Absorbance $\left(\mathrm{cm}^{-1}\right)$ & & & & \\
\hline Stretching vibration Si-O/Al-O & $420-500$ & - & - & - & - \\
\hline Symmetric O-Si-O and O-Al-O vibration & $680-850$ & 790,2 & 790,2 & 790,2 & 790,2 \\
\hline External vibration bend Si-O/Al-O & $700-780$ & - & - & - & - \\
\hline Asyimmetric O-Si-O and O-Al-O & $900-1250$ & 1021,3 & 1021,3 & 1021,3 & 1021,3 \\
\hline Vibration bend $\mathrm{H}-\mathrm{O}-\mathrm{H}$ & $1630-1640$ & 1625,1 & 1625,1 & 1625,1 & 1625,1 \\
\hline Overlap asymmetric and symmetric $\mathrm{H}-\mathrm{O}-\mathrm{H}$ & $3000-3700$ & 3623,0 & 3623,0 & 3623,0 & 3623,0 \\
\hline \multicolumn{2}{|c|}{ CTAB (Taffarel and Rubio, 2010) } & \multirow{2}{*}{ ZMS 1} & \multirow{2}{*}{ ZMS 2} & \multirow{2}{*}{ ZMS 3} & \multirow{2}{*}{ ZMS 4} \\
\hline Vibration & Absorbance $\left(\mathrm{cm}^{-1}\right)$ & & & & \\
\hline Asymmetric $-\mathrm{CH}_{2}$ & 2915 & 2944,5 & 2937,1 & 2929,6 & 2922,2 \\
\hline Symetric $-\mathrm{CH}_{2}$ & 2850 & 2840,2 & 2825,3 & 2817,8 & 2810,4 \\
\hline Methylene scissoring & $1461-1476$ & 1446,2 & 1446,2 & 1446,2 & 1446,4 \\
\hline
\end{tabular}

According to Hongping, et al. [6], at high CTAB concentrations, the frequency range is at a lower wave number because the band of asymmetric $\mathrm{CH} 2$ stretch adsorption is at all-trans conformation. At low CTAB concentrations, the frequency shifts significantly at higher wave numbers indicating that a large number of amine chains are in conformer gauche. At a wavelength of $1446.2 \mathrm{~cm}-1$ that appears in FTIR ZMS 1 spectra, ZMS 2, ZMS 3, and ZMS 4 reinforce the assumption that Lampung Natural Zeolite has been successfully modified with CTAB because at that wavelength occurs methylene scissoring, vibration $\mathrm{N}-(\mathrm{CH} 3)$ which is found in the active group of CTAB surfactant chains. 


\subsection{X-RAT DIFFRACTION (XRD)}

XRD analysis was carried out at the Instrumentation Physics Laboratory of the Faculty of Mathematics and Natural Sciences, Padang State University. CTAB modified XRD zeolite is shown in Figure 2. XRD qualitative characterization can be carried out to determine the type of crystal by comparing diffracted peaks with standard diffractogram data.

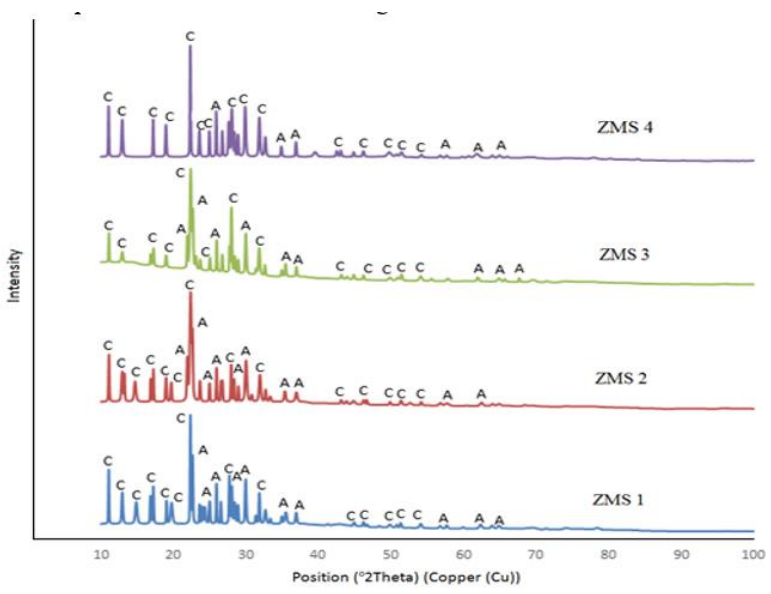

Figure 2 Analysis of XRD on Surfactant Modified Zeolite. $\mathrm{C}$ : Clinoptilolite $\left(\mathrm{Na}_{8}\left(\mathrm{Al}_{6} \mathrm{Si}_{30} \mathrm{O}_{72}\right)\left(\mathrm{H}_{2} \mathrm{O}\right)_{9,04}\right)$ and $\mathrm{A}$ : Albite $\left(\mathrm{Na}\left(\mathrm{Al}_{3} \mathrm{O}_{8}\right)\right)$

Characterization of modified CTAB zeolite showed several peaks with $2 \Theta$ diffraction angles, including $22.33^{\circ} ; 22.63^{\circ} ; 11.07^{\circ} ; 27.70^{\circ} ; 25.92^{\circ}$ at $0.5 \mathrm{mM}$ treatment, while at $1 \mathrm{mM}$ treatment shows a peak with a diffraction angle of $2 \Theta$, including $22.35^{\circ} ; 22.63^{\circ} ; 11.10^{\circ}$; $27.95^{\circ} ; 21.89^{\circ}$. For the treatment of $10 \mathrm{mM}$ it shows several peaks with a diffraction angle of $2 \theta$, including $22.35^{\circ} ; 27.98^{\circ} ; 22.65^{\circ} ; 29.96^{\circ} ; 21.89^{\circ}$, while the treatment of $100 \mathrm{mM}$ shows peaks with a diffraction angle of $2 \Theta$, including $22.3^{\circ} ; 25.89^{\circ} ; 11.05^{\circ} ; 29.87^{\circ}$; $28.0^{\circ}$. This data is then compared to the ICSD standard using POWD-12 ++. The ICDS standard says peak data at an angle of $2 \theta 22.33^{\circ} ; 22.63^{\circ} ; 11.07^{\circ} ; 25.92^{\circ} ; 22.35^{\circ}$; $22.62^{\circ} ; 11.10^{\circ} ; 21.89^{\circ} ; 22.65^{\circ} ; 29.96^{\circ} ; 22.31^{\circ} ; 25.89^{\circ}$; $11.05^{\circ} ; 29.87^{\circ}$ which shows the peak of the clinoptilolite identity. Whereas $27.70^{\circ} ; 27.95^{\circ} ; 27.98^{\circ} ; 28.03^{\circ}$ which is the peak of the albite identity. From the results of XRD ZMS 1, ZMS 2, ZMS 3, and ZMS 4 analysis shows that the clinoptilotite mineral is the dominant phase in natural zeolite used.

Lampung Natural Zeolite was reported to contain $78 \%$ of clinoptilolite, $14 \%$ of analcime, and $8 \%$ of mordenite. Components of natural zeolite which originally consisted of the clinoptilolite, mordenite, and analcime changed slightly after the modification process. This is indicated by the change in mordenite and analcime into albite. So based on the results of X-ray diffractogram shows the addition of CTAB surfactant to natural zeolites will have an effect or influence on the material structure.

\subsection{SCANNING ELECTRON MICROSCOPY (SEM)}

SEM analysis was carried out at the Organic Chemistry Laboratory of University of Lampung. SEM analysis aims to determine the surface morphology of the synthesized zeolite. The following are the results of SEM analysis for the four samples presented in Figure 3.
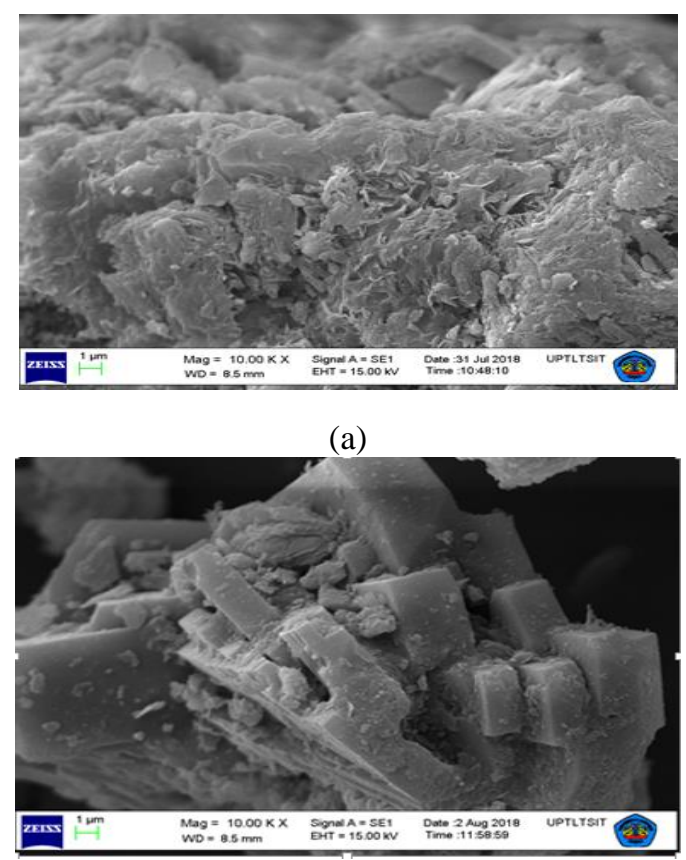

(b)

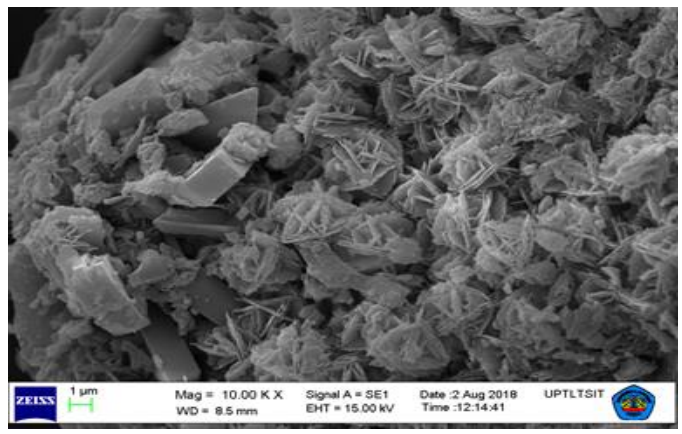

(c)

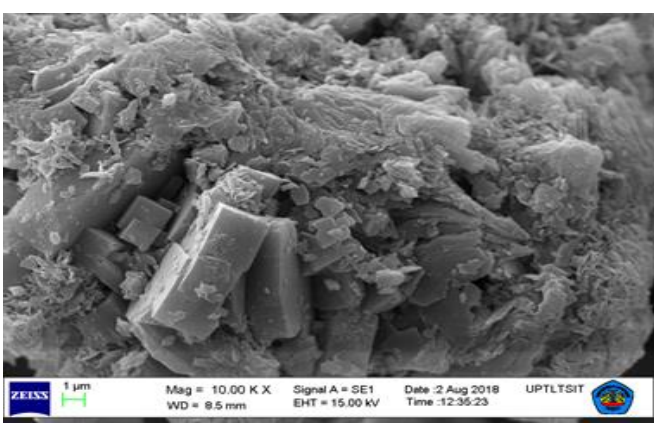

(d)

Figure 3 Morphology of ZMS Produced Through SEM Analysis (a) ZMS 1 (b) ZMS 2 (c) ZMS 3 (d) ZMS 4 
Based on the results of SEM analysis through a magnification of up to 10,000 times it can be seen that for ZMS 1 it has an identical morphological structure that is amorphous. Whereas for ZMS 2, ZMS 3, and ZMS 4 have identical morphological structures consisting of many crystals and slightly amorphous. In ZMS 3 and ZMS 4 it can be seen that CTAB surfactant can stick to the surface of zeolite. This showedby the presence of white spots that appear on the surface of zeolites.

\subsection{Brunauer - Emmet - Teller (BET)}

BET analysis was conducted at the Instrumentation Chemistry Laboratory, Semarang State University. The BET analysis method is by adsorption-desorption of nitrogen for the loop type hierarchy in the material. Nitrogen adsorption isotherm is shown in Figure 4. In this figure it can be seen that nitrogen adsorption isotherm shows a similar pattern where large amounts of nitrogen molecules are adsorbed at low pressure $\mathrm{P} / \mathrm{P}_{0}=$ 0.0 to pressure 0.05 . Then, nitrogen adsorption increases at a relatively low $\mathrm{P} / \mathrm{P}_{0}$ pressure, then slowly increases in the middle. Furthermore, at the relative pressure $\mathrm{P} / \mathrm{P}_{0}=$ 0.4 until the pressure close to 1 increase with the amount of nitrogen gas adsorbed increases. This gradual increase indicates that the four adsorbents have pores that are not uniform in size. Increasing the amount of adsorbed nitrogen gas is due to the adsorbent having a large enough pore [10]. Based on the IUPAC (International Union of Pure and Applied Chemistry) classification, ZMS has H3 type hysteresis loops or loops that show wide slit pore shapes. Branching is caused by the phenomenon of capillary condensation that occurs in the pore material. Characteristics of porous solids can be seen from the graph data of pore size distribution with Barrett, Joyner and Halenda (BJH) shown in Figure 5.

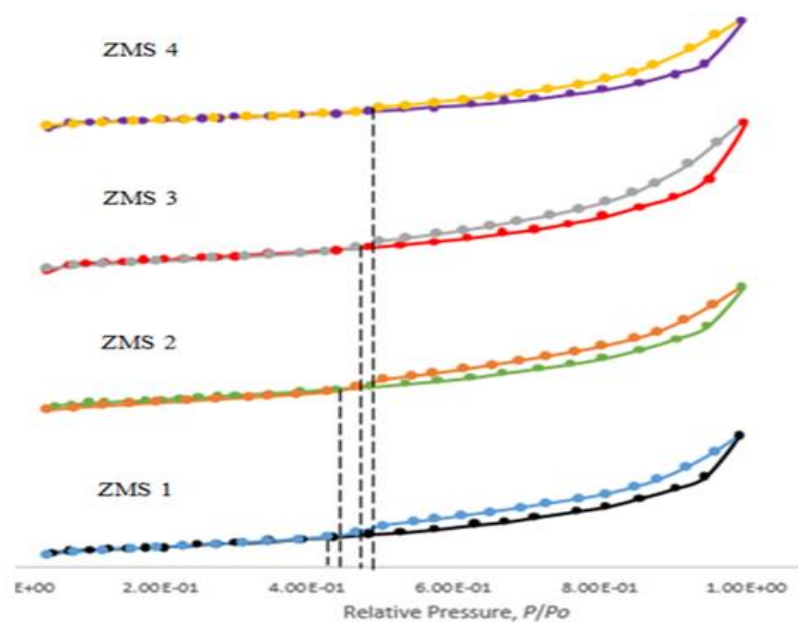

Figure 4Isotherm Curve of Nitrogen Adsorption Desorption on The Zeolite Modified Surfactant

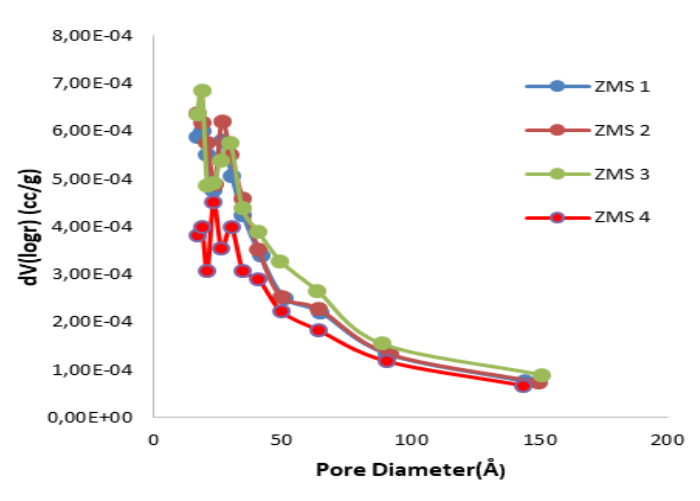

Figure 5 Distribution of Pore Size on Surfactant Modified Zeolite

Pore distribution data in Figure 5 shows that zeolite CTAB surfactant modification (ZMS) has a non-uniform pore size but is still susceptible to micropore and mesoporous i.e., 10-60 Á. The pore size of the material is classified into 3 groups, including the micropore area $(<20 \AA)$, the mesopore region $(20 \AA-500 \AA)$ and the macropore region $(>500 \AA)$. Using the BET method then, will obtain specific surface area, pore volume, and pore size presented in Table 2.

Table 2. BET Analysis of ZMS

\begin{tabular}{|c|c|c|c|}
\hline Sample & $\begin{array}{c}\text { Area } \\
\left(\mathrm{m}^{2} / \mathrm{g}\right)\end{array}$ & $\begin{array}{c}\text { Pore volume } \\
(\mathrm{cc} / \mathrm{gram})\end{array}$ & $\begin{array}{c}\text { Pore size } \\
(\AA)\end{array}$ \\
\hline ZMS 1 & 18.136 & 0.0485 & 53.5704 \\
\hline ZMS 2 & 19.762 & 0.0570 & 50.3101 \\
\hline ZMS 3 & 15.870 & 0.0408 & 71.9410 \\
\hline ZMS 4 & 10.893 & 0.0472 & 74.9755 \\
\hline
\end{tabular}

\subsection{ADSORPTION OF TAPIOCA WASTEWATER}

The highest reduction in COD concentration was found in ZMS 4 of $48.8 \%$. This shows that the addition of higher CTAB concentrations causes the alkyl chains in the surfactant molecules to interact hydrophobically to form a bilayer which makes the outer surface of the zeolite positive. This positively charged outer surface is capable of organic compounds found in waste. This adsorption occurs because of the hydrophobic interaction between modified CTAB zeolite material and non-polar organic matter. Decreasing non-polar organic matter will reduce COD levels in tapioca wastewater.

Table 3. Adsorption Experiment

\begin{tabular}{|c|c|c|c|}
\hline Sample & COD。 & COD $_{\mathrm{t}}$ & Percentage COD \\
\hline ZMS 1 & $967 \mathrm{mg} / \mathrm{L}$ & $694 \mathrm{mg} / \mathrm{L}$ & $28.2 \%$ \\
\hline ZMS 2 & $967 \mathrm{mg} / \mathrm{L}$ & $652 \mathrm{mg} / \mathrm{L}$ & $32.3 \%$ \\
\hline ZMS 3 & $967 \mathrm{mg} / \mathrm{L}$ & $578 \mathrm{mg} / \mathrm{L}$ & $40.2 \%$ \\
\hline ZMS 4 & $967 \mathrm{mg} / \mathrm{L}$ & $495 \mathrm{mg} / \mathrm{L}$ & $48.8 \%$ \\
\hline
\end{tabular}




\section{CONCLUSION}

The spectra of ZMS $100 \mathrm{mM}$ have been successfully modified with CTAB. It is then characterized by absorption peaks at wave number $2922.2 \mathrm{~cm}^{-1}$ and $2810.4 \mathrm{~cm}^{-1}$. It is getting sharper than the previous three ZMS. Characterization of X-ray Diffraction for CTAB modified zeolite shows several peaks with $2 \theta$ diffraction angles that are identical to the peak identities of clinoptilolite and albite. SEM analysis through a magnification of up to 10,000 times it can be seen that ZMS 4 have identical morphological structures consisting of many crystals and slightly amorphous. Based on the material performance in adsorbing tapioca wastewater, the highest percentage of COD reduction was found in ZMS 4 adsorption with a pore average size of $74.9755 \AA$, surface area of $10.893 \mathrm{~m}^{2} / \mathrm{g}$ is $48.8 \%$.

\section{ACKNOWLEDGMENT}

The author would like to thank Universitas Lampung and Institut Teknologi Sumatera for supporting this research.

\section{REFERENCES}

[1] Badan Pusat Statistik (BPS) 2015 Jakarta.

[2] Darmansyah, S.B. Ginting, A. Lisa, S. Hens, 2017, Mesopori MCM-41 sebagai Adsorben: Kajian Kinetika dan Isotherm Adsorpsi Limbah Cair Tapioka Jurnal Rekayasa Kimia dan Lingkungan, VOL. 11(1): 10-17

[3] S.K. Ghadiri, M.A.H. Nabizadeh, S, Nasseri, H. Kazemian, A.R. Mesdaghinia, S. Nazmara, 2010, Methyl Tert-Butyl Ether Adsorption on Surfactant Modified Natural Zeolites, Journal of Environmental Health Science and Engineering, VOL. 7(3):241-252
[4] S.B. Ginting, 2009, Analisis Kinetika Pertukaran Ion $\mathrm{NH}_{4}^{+}$dan $\mathrm{H}^{+}$pada Zeolit Alam Lampung dengan Shrinking Core Model Jurnal Rekayasa Kimia dan Lingkungan, VOL 7(4)197-204

[5] H. HamdaN, 1992, Introduction to Zeolites: Synthesis, Characterization, and Modification. Kuala Lumpur: Universiti Teknologi Malaysia

[6] H. Hongping, F.L. Ray, Z. Jianxi, 2004, Infrared Study of $\mathrm{HDTMA}^{+}$Intercalated Montmorillonite, Spectrochimica Acta Part A: Molecular and Biomolecular Spectroscopy, 6012 2853-2859

[7] Z. Li, R.S. Bowman, 1998, Sorption of Perchloroethylene by Surfactant-Modified Zeolite as Controlled by Surfactant Loading, Environmental Science \& Technology, VOL 31(15): 2278-2282

[8] M. Thommes, K. Katsumi, V.N. Alexander, P.O. James, R.R. Fransisco, R. Jean, S.W.S. Kenneth, 2015, Physisorption of Gases, with Special Reference to The Evaluation of Surface Area and Pore Size Distribution (IUPAC Technical Report) Pure Appl Chem.

[9] S.R. Taffarel, J. Rubio, 2010, Adsorptions of Sodium Dodecyl Benzene Sulfonate from Aqueous Solution Using a Modified Natural Zeolite with CTAB, Journal of Mineral Engineering 23:771-77.

[10] J.H. Perry et.al., 1997, Chemical Engineers' Handbook $7^{\text {th }}$ Edition New York: McGraw Hill. 